\title{
Mechanical Properties and Wear Behavior of a Novel Composite of Acrylonitrile-Butadiene-Styrene Strengthened by Short Basalt Fiber
}

\author{
Mohammed Y. Abdellah ${ }^{1,2, *}$, Hesham I. Fathi ${ }^{3,4}$, Ayman M. M. Abdelhaleem ${ }^{5}$ and \\ Montasser Dewidar ${ }^{6}$ \\ 1 Mechanical Engineering Department, Faculty of Engineering, South Valley University, Qena 83523, Egypt \\ 2 Mechanical Engineering Department, College of Engineering and Islamic Architecture, \\ Umm Al-Qura University, Makkah 21421, KSA \\ 3 Faculty of Engineering, Aswan University, Aswan 81542, Egypt; hesham.elqady@aswu.edu.eg \\ 4 Chemicals and Petrochemicals Engineering Department, Egypt-Japan University of Science and Technology, \\ New Borg El-Arab City, Alexandria 21934, Egypt \\ 5 Mechanical Design and Production Engineering Department, Faculty of Engineering, Zagazig University, \\ Zagazig 44519, Egypt; aymanmns@hotmail.com \\ 6 Department of Mechanical Engineering, Faculty of Engineering, Kafr El-sheikh University, \\ Kafr El-sheikh 33516, Egypt; Dewidar5@hotmail.com \\ * Correspondence: mohammed_yahya42@yahoo.com; Tel.: +966-546-240-463
}

Received: 12 May 2018; Accepted: 4 June 2018; Published: 7 June 2018

\begin{abstract}
Polymer matrix composites (PMC) have a competitive and dominant role in a lot of industries, like aerospace and automobiles. Short basalt fiber (SBF) is used to strengthen acrylonitrile-butadiene-styrene (ABS) polymers as a composite. The composite material is fabricated using injection molding with a new technique to obtain a uniform distribution for the ABS matrix at an elevated temperature range from $140{ }^{\circ} \mathrm{C}$ to $240{ }^{\circ} \mathrm{C}$. Four types of specimen were produced according to the mechanically mixed amounts of SBF, which were $(5,10,15,20) \mathrm{wt} \%$. The produced material was tested for tension, hardness and impact to measure the enhancement of the mechanical properties of the ABS only and the ABS reinforced by SBF composite. Wear tests were carried out using a pin on disc at a velocity of $57.5 \mathrm{~m} / \mathrm{s}$ at three normal loads of 5,10 and $15 \mathrm{kN}$. Tensile strength increased with up to $5 \mathrm{wt} \%$ of SBF, then decreased with an increasing amount of SBF reinforcement, while surface hardness increased with increasing SBF. The impact strength was found to degrade with the whole increment of SBF. Wear resistance increased with the increasing SBF reinforcement amount at all applied normal loads.
\end{abstract}

Keywords: acrylonitrile-butadiene-styrene (ABS); short basalt fiber (SBF); wear resistance; hardness; impact energy

\section{Introduction}

Composite materials nowadays play an increasing role in a lot of applications, such as the aerospace and automobile industry, and finally in biomedical applications. Acrylonitrilebutadiene-styrene (ABS) polymer plays an important role in many engineering plastics and composite materials, and has a rubber polybutadiene structure [1]. Natural fibers, like basalt fiber, nowadays plays a competitive role and receives special consideration compared to conventional glass and carbon fiber, because of their low cost and close mechanical and chemical properties [2-5].

Jiang et al. [6] investigated the effect of strengthening ABS with calcium carbonate particles of micro and nano size. They concluded that the microcrystalline cellulose/acrylonitrile-butadiene- 
styrene (MCC/ABS) composite had a higher relative elastic modulus and lower relative tensile and impact strength when compared with ABS alone, while in Sept et al. [7], it was proved that particle size and heat treatment have little effect on the mechanical, thermal and physical properties of ABS.

Abdel-Haleem et al. [8] strengthen ABS using basalt fiber (BF). They used an injection molding machine to manufacture the BF/ABS composite with a varying wt $\%$ of BF. They investigated the effect of the basalt fiber content on the tensile and impact strength, and on hardness. They concluded that both tensile strength and Rockwell hardness improved with the increased wt $\%$ of $\mathrm{BF}$, while the impact strength decreased.

Lopresto et al. [9] compared the mechanical performance of basalt fiber and glass fiber, and found that basalt fiber produces a higher Young's modulus, compressive strength, and impact strength. They reported that low-cost basalt fiber is more competitive in glass fiber applications.

Difallah et al. [10] investigated the mechanical and tribological properties of ABS filled with graphite powder. It was observed that increasing the graphite content in the ABS matrix led to a drastic decrease in tensile strength, while it produced a good enhancement of the tribological properties and friction coefficient; this was possibly due to the fact that graphite powder is a solid lubricants.

Colombo et al. [11] used basalt fiber to strengthen the polymer matrix. They needed to study the effect of basalt fiber on the mechanical properties. The results showed that high mechanical properties were achieved for both tensile and compressive behavers, moreover, the failure modes were found to be more tight and concise.

Jeevanantham et al. [12] experimentally investigated the tensile and flexural strength of polyurethane reinforced by basalt fiber composite laminate. The composite laminate was fabricated using a match plate mold under $1500 \mathrm{~kg}_{f} / \mathrm{cm}^{2}$ for $4 \mathrm{~h}$ at room temperature. They studied the effect of varying weight fractions of basalt fiber. It resulted in good tensile and flexural strength up to a certain weight fraction.

Chen et al. [13] carried out quasi-static and dynamic tests on unidirectional basalt-fiber-reinforced polymer (BFRP) to study the tensile properties of such a material. They observed that the tensile properties of BFRP were strain rate sensitive, they also extracted a good empirical formulation for predicting tensile properties. Khosravi and Farsani [14] attempted to enhance the mechanical properties of a unidirectional basalt fiber/epoxy composite using a modified nanoclay. Scalici et al. [15] carried out work on a basalt-fiber-reinforced composite using different vacuum-assisted impregnation techniques.

Wu et al. [16] investigated the durability of a basalt-fiber-reinforced epoxy composite in a different corrosive medium. It was found that the basalt fiber showed relatively strong resistance to water and salt corrosion, reasonable resistance to acid corrosion, and bad resistance in alkaline liquids.

Many studies have been carried out on continuous and short basalt fiber as a reinforcement phase [17-31].

Basalt fiber is natural fiber that is produced by basalt rock, this makes their chemical, physical and mechanical properties sensitive to the type of raw material, technology, and method of obtaining the final product $[9,32]$. Therefore, reinforcement plastic with this type of material needs a lot of investigation and studies.

Sudeepan et al. [33] studied the effect of varying micro-size zinc oxide (Zno) contents in a matrix of ABS polymer on the mechanical and tribological properties. It was concluded that tensile and flexural modulus and hardness generally increase with increasing filler content, whereas tensile and flexural strength increased up to $15 \mathrm{wt} \%$, before decreasing again. They also reported the enhancement of the wear and friction coefficient with the filler content.

Zhang et al. [34] fabricated a short-basalt-fiber-reinforced polyamide product and filled it with $\mathrm{MOS}_{2}$ and graphite contents using a hot press molding technique. The tribological properties of the composite product were investigated with a model ring-on block test rig, whereas the wear mechanism was studied based on scanning electron microscope examination. It was concluded that the tribological properties were improved with the filler contents. 
Ha et al. [35] experimentally investigated the corrosion and tribological properties of basaltfiber-reinforced composites. The corrosion effect was based on time and $\mathrm{H}_{2} \mathrm{SO}_{4}$ concentration. It was summarized that there was a general increase in specimen weight after corrosion in $\mathrm{H}_{2} \mathrm{SO}_{4}$ due to basalt fiber precipitate. The friction coefficient and wear behavior were irregular, while afterwards corrosion friction coefficient was two or three times greater.

The present study had three major main goals, which can be summarized as follows:

(1) Fabrication of a novel composite material using ABS reinforced for the first time with short basalt fiber (SBF).

(2) Measure the mechanical characteristic properties and durability of the new composite.

(3) Measure the wear behaviors and wear mechanism of the novel composite.

The authors in [8] carried out a similar study, but using long basalt fiber, and without studying the tribological properties.

The paper structured as follows: in the first section the materials are described, in the second section the manufacturing technique for the composite sample is summarized, in the third section the mechanical and wear tests are explained, and finally the results and discussion are followed by the conclusion, where the best results are considered.

\section{Materials and Methods}

The work was performed using ABS that was supplied by LG Chem, Ltd., Hwachi-Dong, Yeosu-City, Jeonaranam-Do, 550-280, Korea. It is of RX710 grade, has a melting flow index of $21 \mathrm{~g} / 10 \mathrm{~min}$ and a density of $1.04 \mathrm{~g} / \mathrm{cm}^{3}$ [36]. The reinforcement of SBF was of 3:50 $\mu \mathrm{m}$ length and less than $6.5 \mu \mathrm{m}$ in diameter, and was supplied by ROCKAL Co. (Cairo, Egypt) [37]. Figure 1 shows the raw materials of the composite product; their specifications are listed in Table 1 . The basalt fiber as an inorganic material reinforcement has no homogeneity in melt [38]. It has many forms: fibrous, short or it may yarn [39].

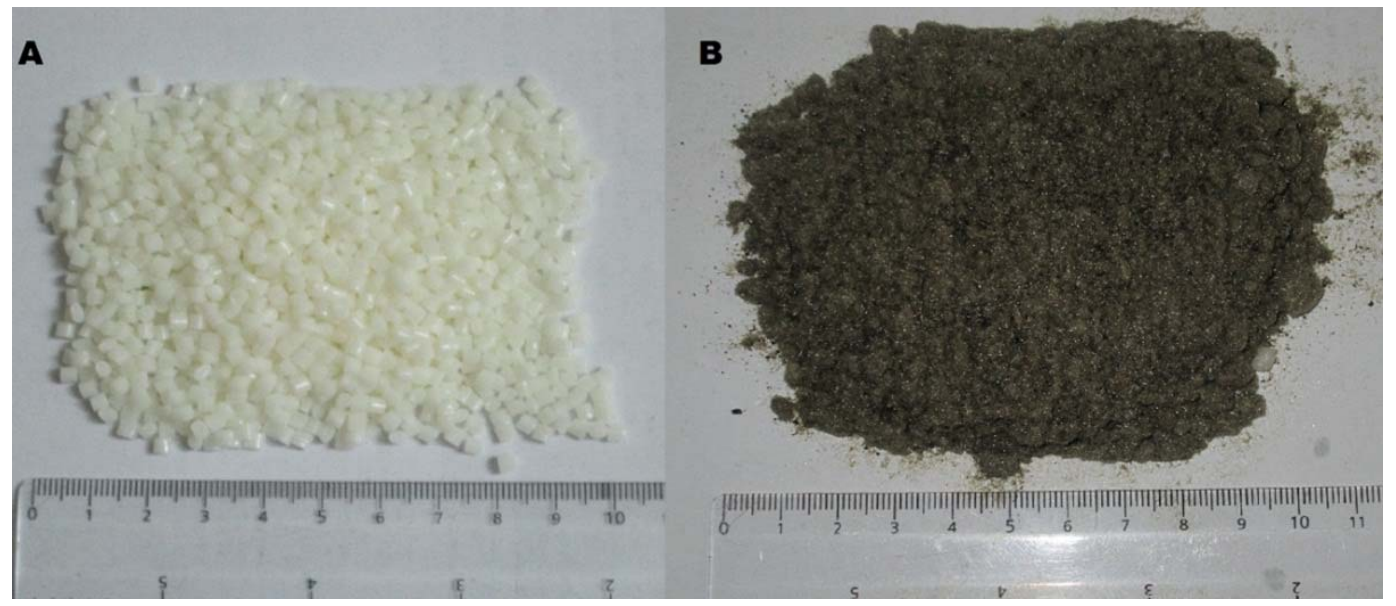

Figure 1. Composite raw material. (A) acrylonitrile-butadiene-styrene (ABS); (B) Short basalt fiber (SBF).

Table 1. Specification of the raw material of the composite.

\begin{tabular}{ccccc}
\hline Raw Material & Density $\left(\mathrm{g} \cdot \mathrm{cm}^{-3}\right)$ & $\begin{array}{c}\text { Melt Flow Index } \\
(\mathrm{g} / \mathbf{1 0} \mathbf{~ m i n})\end{array}$ & Particle Size $(\mu \mathrm{m})$ & Diameter $(\mu \mathrm{m})$ \\
\hline $\begin{array}{c}\text { Acrylonitrile-butadiene-styrene (ABS) } \\
\text { Short basalt fiber (SBF) }\end{array}$ & 1.04 & 21 & - & - \\
\hline
\end{tabular}




\section{Sample Preparation}

The specimens were manufactured using reciprocating screw injection molding (HAITIAN PL 1200, Haitian International Holdings Limited, Ningbo, China). The working range of temperatures of the barrel along the injection molding machine was $140{ }^{\circ} \mathrm{C}, 170{ }^{\circ} \mathrm{C}, 220^{\circ} \mathrm{C}$ and $240{ }^{\circ} \mathrm{C}$, as listed in Table 2 . The ABS was dried at $12{ }^{\circ} \mathrm{C}$ for nearly $5 \mathrm{~h}$ to avoid possible moisture degradation. The SBF was mechanically mixed with ABS by $(5,10,15$, and 20$) \mathrm{wt} \%$. The direction of the polymer plastic flow was controlled to be unidirectional for all produced specimens, this is to avoid the weld line, which can lead to weakness and cracks. The mold of the injection molding machine is explained in [8]. The standard specimens were all $4 \mathrm{~mm}$ thickness for the tension test, $5 \mathrm{~mm}$ for the impact test and $6 \mathrm{~mm}$ for the wear test.

Table 2. Conditions of the injection molding machine.

\begin{tabular}{cccccc}
\hline Parameter Pressure in (Bar) & First Stage & Second Stage & Third Stage & Fourth Stage & Fifth Stage \\
\hline Injection & 140 & 140 & 140 & 130 & 130 \\
Closing & 80 & 80 & 80 & 30 & 100 \\
Holding & 100 & 100 & 100 & - & - \\
Opening & 60 & 60 & 60 & 60 & 60 \\
Charging & 100 & 100 & 100 & - & - \\
\hline
\end{tabular}

\section{Mechanical and Wear Testing}

All the produced specimens of SBF-reinforced ABS composite were tested in tension according to the ASTM D3039/[40] at room temperature and 50\% relative humidity. The tensile test was carried out using the one-ton capacity universal testing machine at $5 \mathrm{~mm} / \mathrm{min}$ crosshead speed. The dog bone tensile test specimen is shown in Figure 2 with dimensions. The Charpy impact test was performed on all specimens accord to ASTM D6110-17 [41] at room temperature using a $5 \mathrm{~kg}$ hummer (see standard sample Figure 2b). The Rockwell hardness test, which is based on the Rockwell C-method, was carried out using a Digital Rockwell Hardness Tester, HRS-150 (Beijing United Test Co., Ltd., Beijing, China), the test was performed at room temperature according to the ASTM D785-08 standard [42]. The wear test was carried out on all produced specimens according to the ASTM G132-96 standard [43] at room temperature and $57.5 \mathrm{~m} / \mathrm{s}$ using a pin on disc device, the counter face of the abrasive disc was of surface roughness (p1000). The weight loss was measured for each specimen at various normal load $(5,10$ and 15$) \mathrm{kN}$ before and after the test. A microstructure examination of the fractured SBF-reinforced ABS composite with the tension and damage surface in the wear test were investigated using JEOL JSM.5500LV (JEOL Ltd., Tokyo, Japan) scanning electron microscopy at an acceleration voltage of $25 \mathrm{kV}$ after immersion in nitrogen gas medium. The fractured and damaged surface was coated with a very thin layered of gold. Modes of failure were observed optically using a high-resolution digital camera for tension test samples.

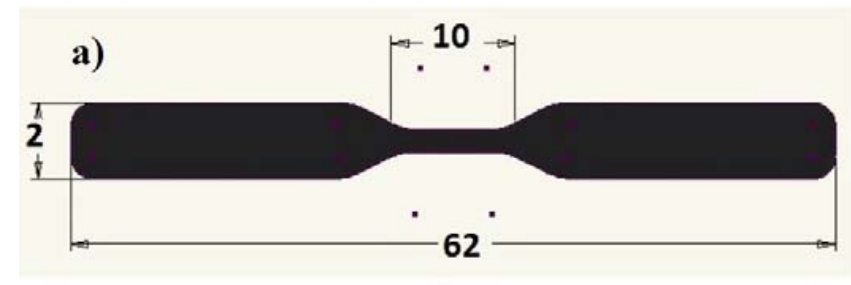

b)

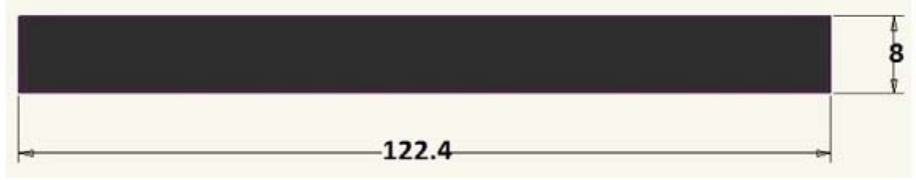

Figure 2. Standard specimen (a) Tension test; (b) Impact test. (Unit: mm). 


\section{Results and Discussion}

\subsection{Tension Test}

Figures 3 and 4 a show a stress and strain diagram of SBF-reinforced ABS; it is clear that the composite tensile strength increases with the increasing wt \% of the SBF up to $5 \mathrm{wt} \%$, then it decreases. This trend might be due to the large area size and very weak interface [1]. The ductility of the newly-produced material drastically reduced with the increasing amount of SBF, as is shown in the percentage length elongation curve in Figure $4 \mathrm{~b}$; this can be attributed to the small area of SBF, which causes weak interfaces with the ABS [6]. With the lower content of reinforcement, there was a larger interfacial area, which led to the specimen being able to withstand a larger load capacity. The Young's modulus increased up to $5 \mathrm{wt} \%$ then decreased, this may be due to the low strain when the strain was evaluated (see Table 3). The 3D plot in Figure 5 relates the elongation and tensile strength of the $\mathrm{wt} \%$ of SBF. The failure modes for all tension test specimens were net tension with some surface microcracks, which is observed near the fracture process zone (see Figure 6). Scanning electron microscope (SEM) examinations show a uniformly-distributed matrix of ABS and smooth surface failure without microcracks (see Figure 7a). However, the surface becomes rough with the increasing wt \% of ABS (Figure 7b-e); this can be attributed to the breaking of the bonds between the SBF and ABS, as these bonds cause fiber bridging and pull the matrix to a location of joining. Fiber breaking (marked with rectangular lines) at the interface between the ABS was observed, while fiber pull-out (marked with circular lines) clearly appeared. For the $20 \mathrm{wt} \% \mathrm{SBF}$, the fracture surface shows a random distribution of SBF, which means good mixing with the matrix. Each test was repeated five times and the stem diameter variations (SDV) was calculated and is listed in Table 3.

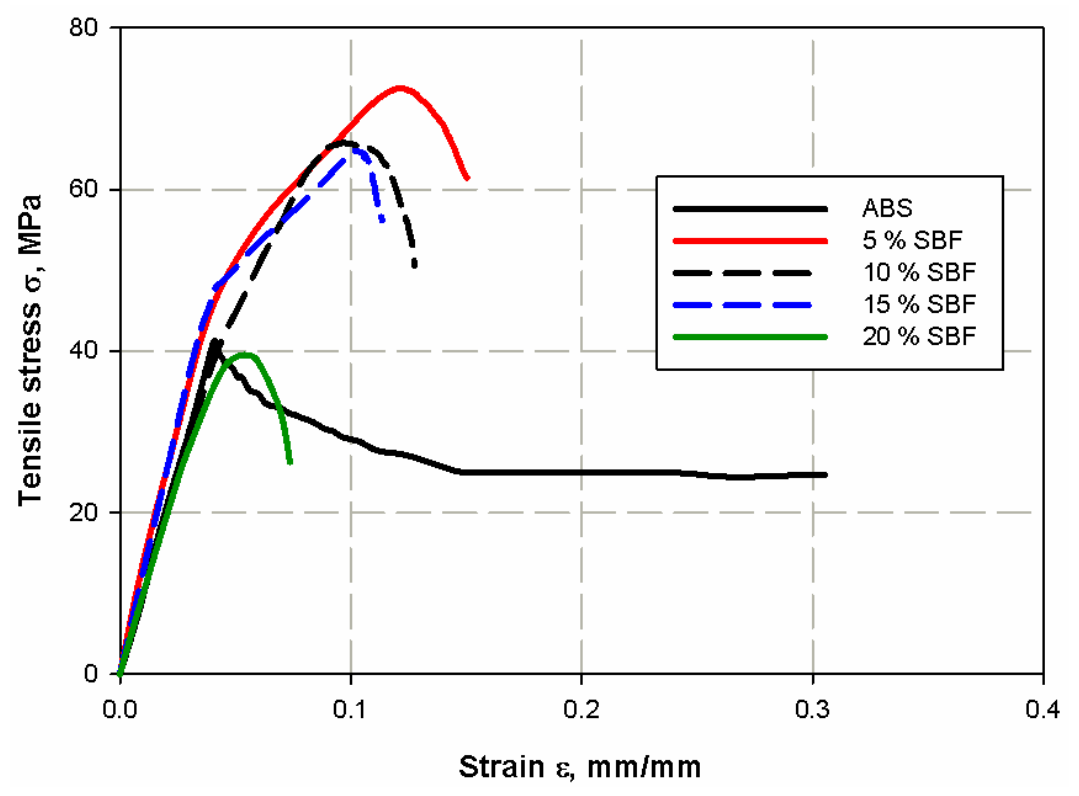

Figure 3. Stress-strain diagram for short basalt fiber (SBF)-reinforced acrylonitrile-butadiene-styrene (ABS). 


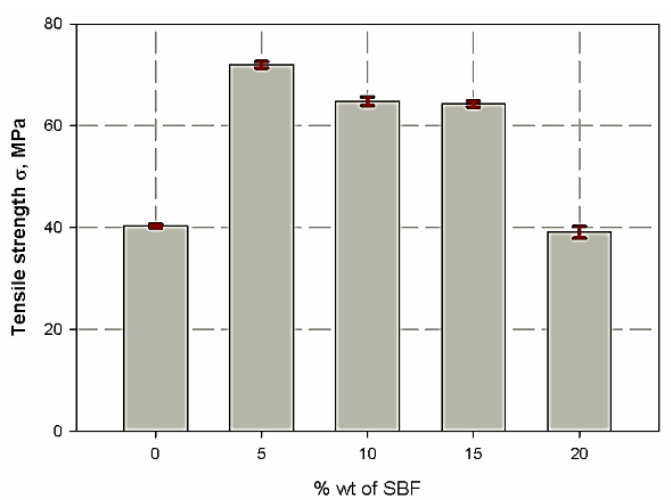

a)

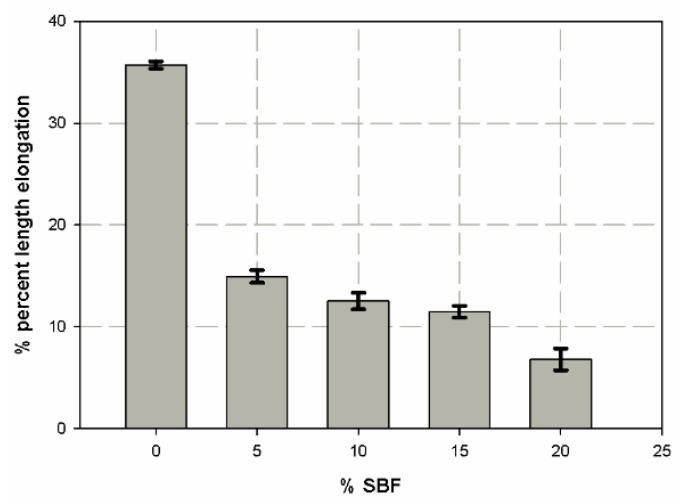

b)

Figure 4. Variation with wt \% (a) Tensile strength; (b) Percent elongation.

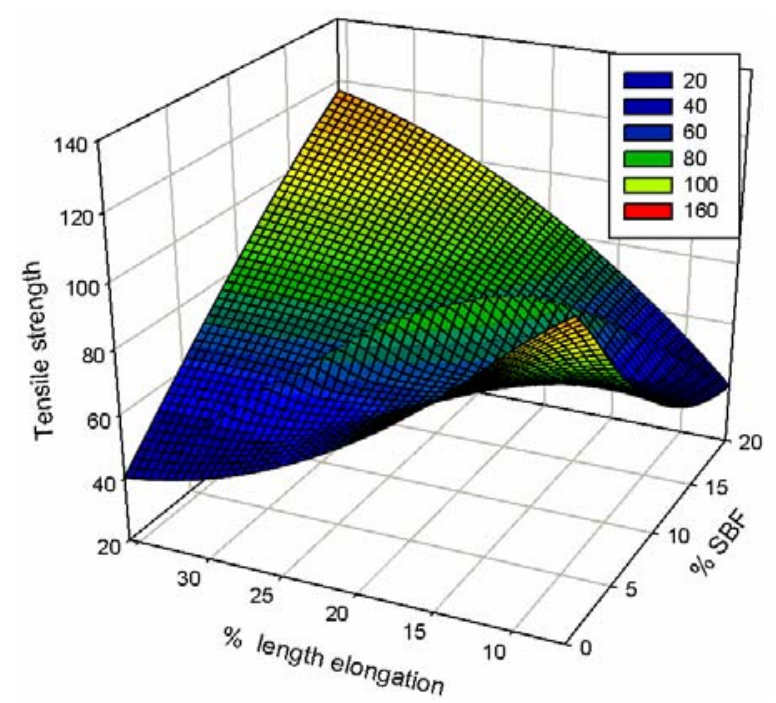

Figure 5. A 3D curve relating the tensile test results with wt \% of SBF reinforcement.

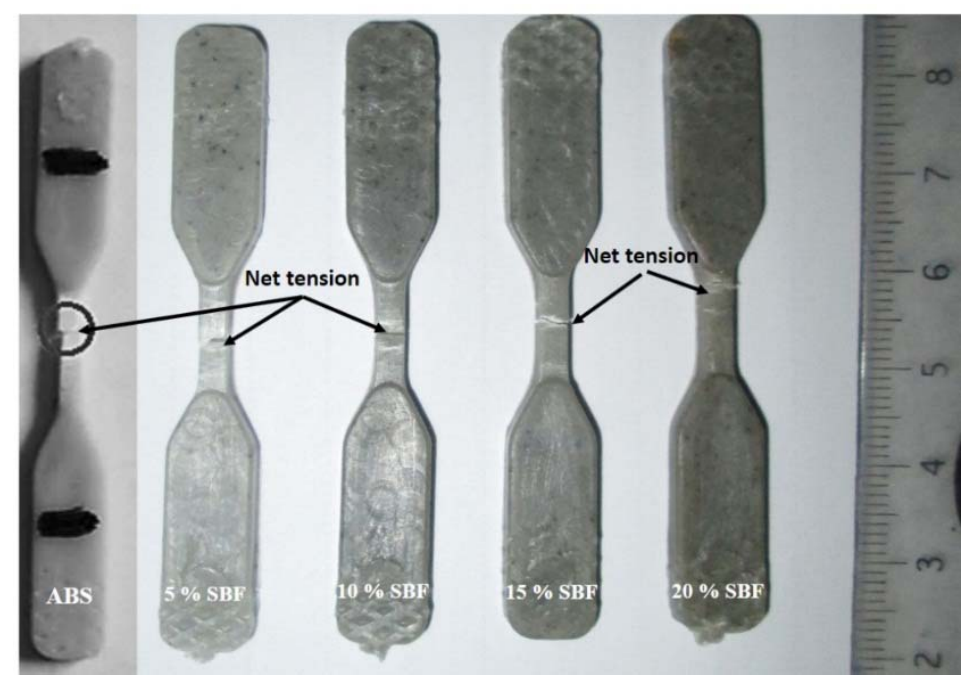

Figure 6. Failure modes in the tensile test specimens. 

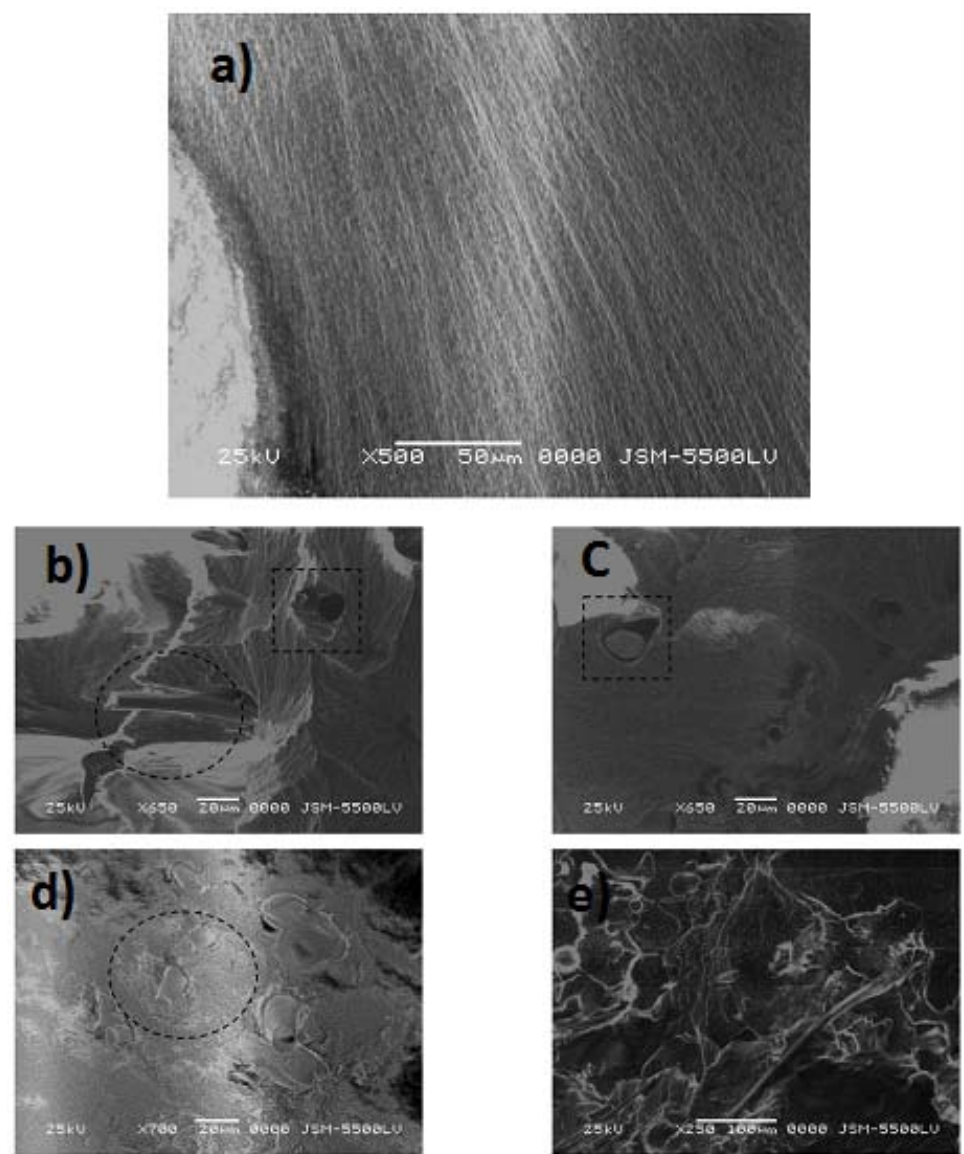

Figure 7. Scanning electron microscope (SEM) microstructure examination of fracture plane (a) ABS; (b) $5 \mathrm{wt} \% \mathrm{SBF}$; (c) $10 \mathrm{wt} \%$; (d) $15 \mathrm{wt} \%$; (e) $20 \mathrm{wt} \%$.

Table 3. Tensile test results.

\begin{tabular}{cccccc}
\hline Samples & Tensile Strength (MPa) & SDV & Elongation at Break (\%) & SDV & Young's Modulus (MPa) \\
\hline ABS & 40.32 & 0.36 & 35.7 & 0.36 & 1450 \\
ABS + 5\%SBF & 72.69 & 0.63 & 14.94 & 0.62 & 1481 \\
ABS + 10\%SBF & 64.82 & 0.82 & 12.53 & 0.81 & 1099.7 \\
ABS + 15\%SBF & 64.29 & 0.58 & 11.46 & 0.57 & 1117.2 \\
ABS + 20\%SBF & 39.07 & 1.16 & 6.79 & 1.062 & 871.3 \\
\hline
\end{tabular}

\subsection{Hardness and Impact Tests}

Figure 8 shows results of the Rockwell hardness test $(\mathrm{RH})$. It is clearly illustrated that with the increasing wt \% of SBF in the ABS matrix, the (RH) increased. This is due to the increasing amount of brittle SBF, which resists penetration through the material's composite surface. The impact strength represented by the released energy stored in the material was reduced with the increasing wt $\%$ of SBF reinforcement (see Figure 9), due to decreasing ductility. There are two mechanisms for impact strength enhancement in a composite material, one increases the interfacial bond between the polymer and reinforcement, and the other adds a flexible and elastic phase that increases the impact [44]. There are two reasons for impact strength degradation, one is the weakness of interfacial bonding between brittle and high stiffness SBF and ABS, and the other is the cavitation or inner distance between the SBF increase, with an increasing amount of reinforcement phase [45-47]. The fracture surfaces under the impact load were analyzed using SEM photos, which are shown in Figure 10. It is observed that the interaction between the SBF and ABS matrix was poor, with an increasing fiber contents, therefore, a rough surface could be observed. The relation between the Rockwell hardness and impact strength with the variation of the wt \% of SBF is shown in Figure 11. 


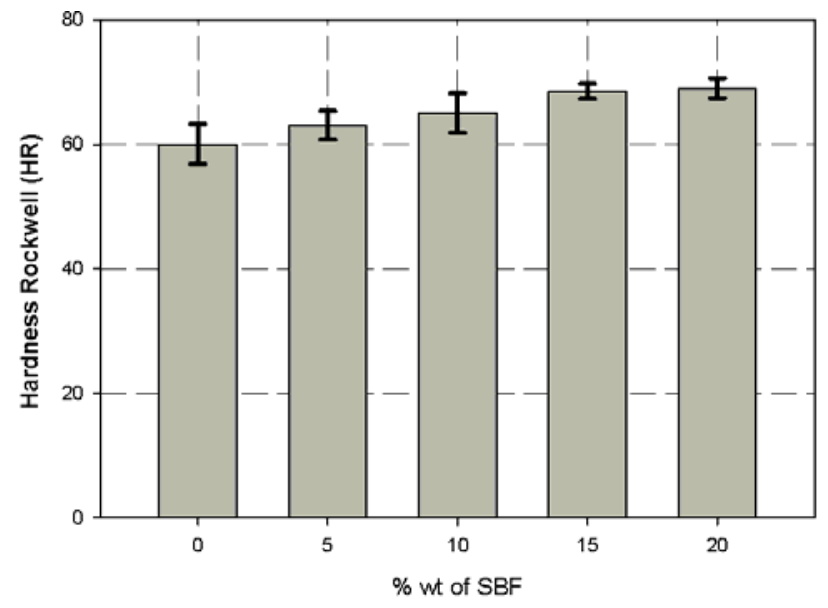

Figure 8. Vickers hardness variation with wt $\%$ of ABS.

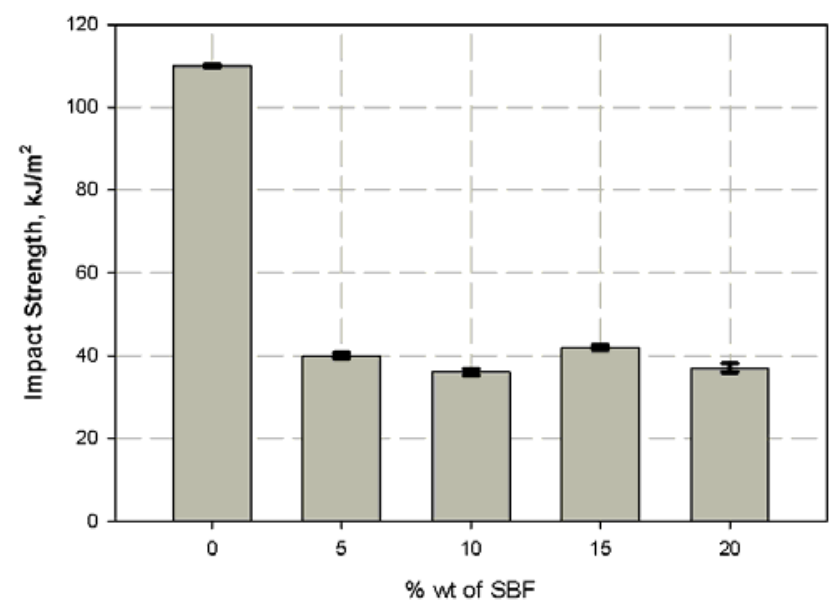

Figure 9. Impact fracture toughness variation with wt \% SBF.
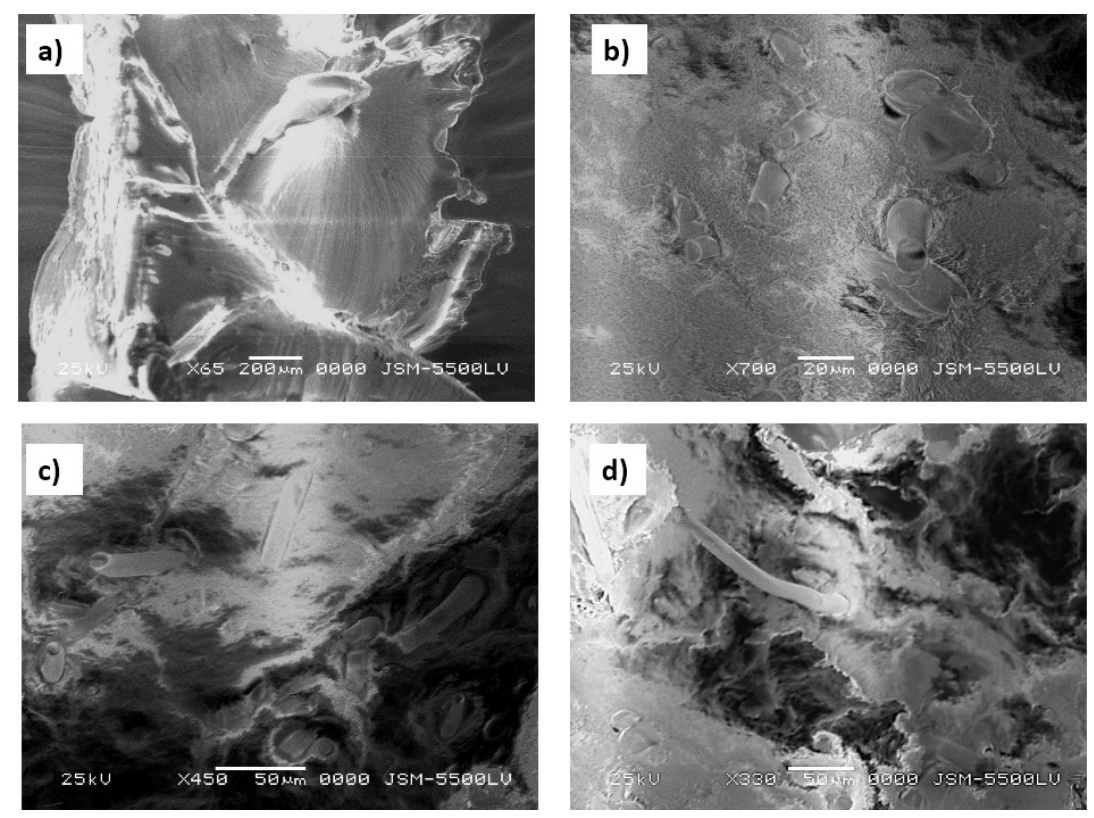

Figure 10. SEM microstructure examination of fracture plane (a) $5 \mathrm{wt} \%$; (b) $10 \mathrm{wt} \%$; (c) $15 \mathrm{wt} \%$; (d) $20 \mathrm{wt} \%$ content SBF. 


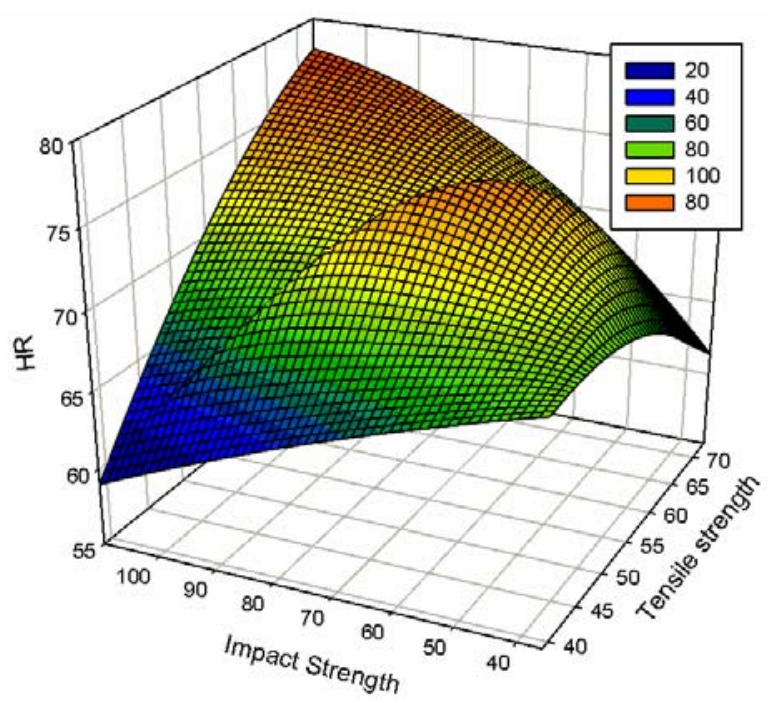

Figure 11. Relation between the impact fracture and hardness with wt \% SBF variation.

\subsection{Wear Test}

The reinforcement phase plays a great role in the tribological behavior and wear of the polymer material, as reported in [48]. The ABS plays an important role in a lot of applications, such as bearing and slide material. Figure 12 shows the weight loss variation with the increasing wt \% of SBF content reinforcement. The SBF is a ceramic material that can be an abrasive agent. This abrasive agent enhances and increases the wear resistance of the composite material. Figure 13 shows a change of weight loss with the variation of normal applied loads and the variation of the wt $\%$ of the SBF. It can be clearly observed that with the increasing normal load, the weight loss increased, while with the increasing wt \% of SBF, the weight loss decreased, which means that the wear resistance was enhanced. A total of $20 \mathrm{wt} \%$ of SBF results in a reduction in weight loss of nearly $78 \%, 82 \%$ and $84 \%$ for $5 \mathrm{kN}$, $10 \mathrm{kN}$, and $15 \mathrm{kN}$ normal loads, respectively. The SEM micrograph of the damaged surface due to wear action is depicted in Figure 14 for ABS and $20 \mathrm{wt} \%$ SBF. The shear action is shown directly over the ABS (see Figure 14a), while for $20 \mathrm{wt} \%$ SBF the shear action interacted directly with the brittle fibers; therefore, an increasing wt \% of SBF reduces the weight loss or wear rate (see Figure 13b). It was also found that the SBF is randomly distributed in the ABS matrix. There is some surface damage and breakage in the SBF fiber; this may be due to weak interfacial bonding between the SBF and ABS matrix.

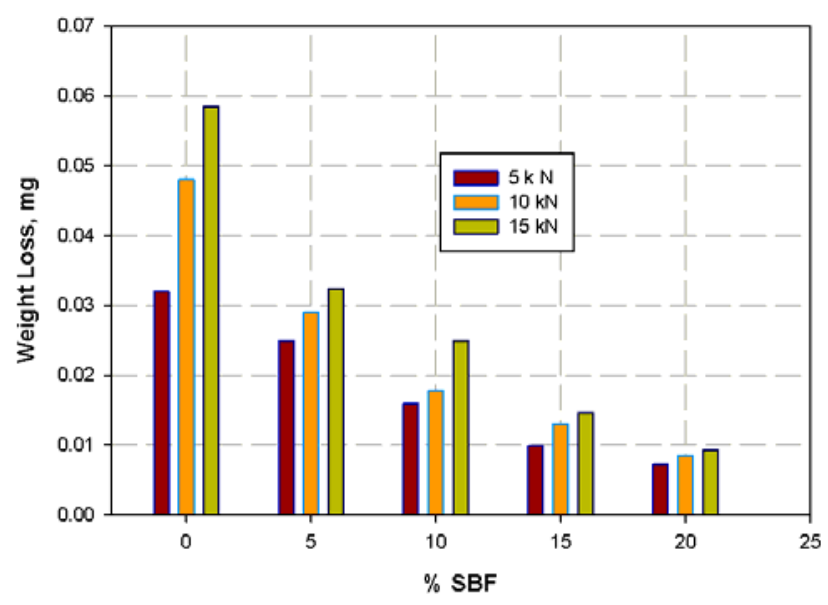

Figure 12. Wear resistance variation with wt \% of SBF. 


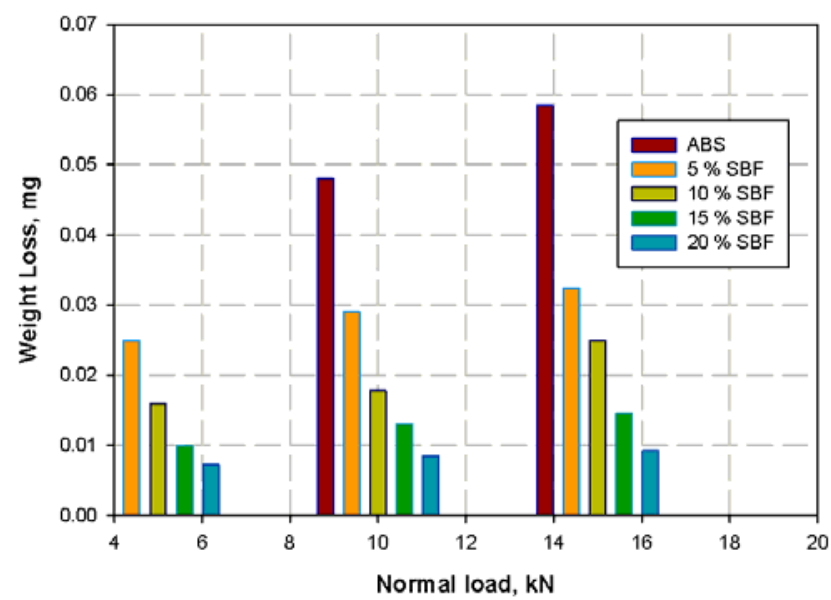

Figure 13. Wear resistance variation with normal load at a variation of wt $\%$ of SBF.
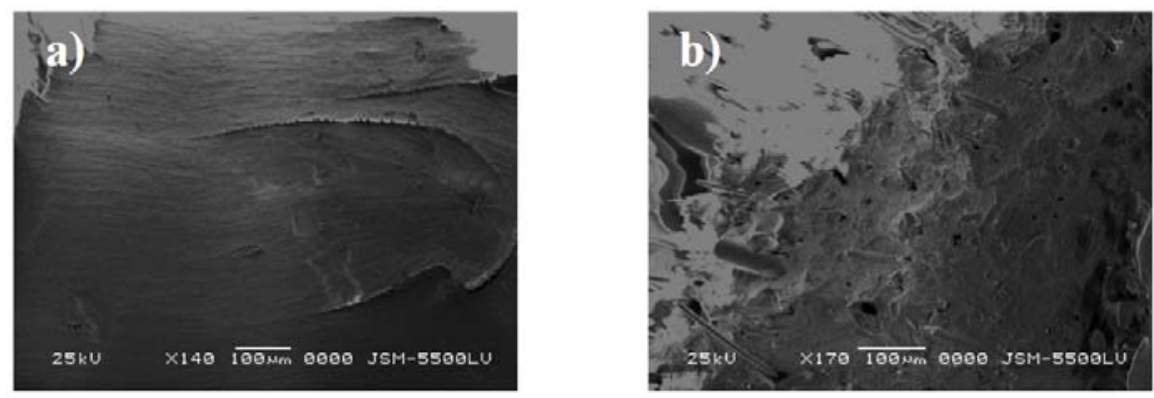

Figure 14. Shear mode in wear test. (a) ABS; (b) SBF.

\section{Conclusions}

Inorganic fillers have been used widely to enhance the mechanical and tribological properties of polymer products at lower cost. When SBF is used as a reinforcement in an ABS matrix, it is an inorganic material found to have weak interfacial bonding with the ABS. Increasing the wt $\%$ of the SBF content in the ABS matrix enhanced both the surface hardness and wear strength, while the weakness of the interfacial bonding between the fiber and the ABS led to decreased impact strength. Moreover, the tensile strength as well as the percent elongation in general decreased with the increasing $\mathrm{wt} \%$ of SBF. It can be clearly concluded that the SBF is randomly distributed in the ABS matrix. The SBF failure mechanism may be fiber pull-out, fiber breakage and an absence of matrix carking. To enhance the tensile strength of a composite with an ABS base matrix, the SBF content should not exceed $5 \mathrm{wt} \%$.

Author Contributions: Conceptualization, Validation, Formal Analysis, writting and Methodology, M.Y.A. and H.I.F., Software and Writing-Review \& Editing, A.M.M.A. and M.D.

Funding: This research received no external funding.

Acknowledgments: Faculty of engineering energy at university of Aswan due to their continuous help during preforming these works.

Conflicts of Interest: The authors declare no conflict of interest.

\section{References}

1. Li, Y.; Shimizu, H. Improvement in toughness of poly(L-lactide) (PLLA) through reactive blending with acrylonitrile-butadiene-styrene copolymer (ABS): Morphology and properties. Eur. Polym. J. 2009, 45, 738-746. [CrossRef]

2. Sarasini, F.; Tirillò, J.; Valente, M.; Valente, T.; Cioffi, S.; Iannace, S.; Sorrentino, L. Effect of basalt fiber hybridization on the impact behavior under low impact velocity of glass/basalt woven fabric/epoxy resin composites. Compos. Part A Appl. Sci. Manuf. 2013, 47, 109-123. [CrossRef] 
3. Czigány, T. Trends in fiber reinforcements-the future belongs to basalt fiber. Express Polym. Lett. 2007. [CrossRef]

4. Deák, T.; Czigány, T. Chemical composition and mechanical properties of basalt and glass fibers: A comparison. Text. Res. J. 2009, 79, 645-651. [CrossRef]

5. Czigány, T.; Vad, J.; Pölöskei, K. Basalt fiber as a reinforcement of polymer composites. Period. Polytech. Eng. Mech. Eng. 2005, 49, 3.

6. Jiang, L.; Lam, Y.; Tam, K.; Chua, T.; Sim, G.; Ang, L. Strengthening acrylonitrile-butadiene-styrene (ABS) with nano-sized and micron-sized calcium carbonate. Polymer 2005, 46, 243-252. [CrossRef]

7. Sepet, H.; Tarakcioglu, N.; Misra, R. Determination of the mechanical, thermal and physical properties of nano-CaCO3 filled high-density polyethylene nanocomposites produced in an industrial scale. J. Compos. Mater. 2016, 50, 3445-3456. [CrossRef]

8. Abdelhaleem, A.M.; Abdellah, M.Y.; Fathi, H.I.; Dewidar, M. Mechanical properties of ABS embedded with basalt fiber fillers. J. Manuf. Sci. Prod. 2016, 16, 69-74. [CrossRef]

9. Lopresto, V.; Leone, C.; de Iorio, I. Mechanical characterisation of basalt fibre reinforced plastic. Compos. Part B Eng. 2011, 42, 717-723. [CrossRef]

10. Difallah, B.B.; Kharrat, M.; Dammak, M.; Monteil, G. Mechanical and tribological response of ABS polymer matrix filled with graphite powder. Mater. Des. 2012, 34, 782-787. [CrossRef]

11. Colombo, C.; Vergani, L.; Burman, M. Static and fatigue characterisation of new basalt fibre reinforced composites. Compos. Struct. 2012, 94, 1165-1174. [CrossRef]

12. Jeevanantham, R.; Venketaramanamurthy, V.; Rajeswari, D. Mechanical and wear characterization of basalt fiber reinforced polyurethane composites. Int. J. Adv. Eng. Technol. 2016. [CrossRef]

13. Chen, W.; Hao, H.; Jong, M.; Cui, J.; Shi, Y.; Chen, L.; Pham, T.M. Quasi-static and dynamic tensile properties of basalt fibre reinforced polymer. Compos. Part B Eng. 2017, 125, 123-133. [CrossRef]

14. Khosravi, H.; Eslami-Farsani, R. Enhanced mechanical properties of unidirectional basalt fiber/epoxy composites using silane-modified $\mathrm{Na}^{+}$-montmorillonite nanoclay. Polym. Test. 2016, 55, 135-142. [CrossRef]

15. Scalici, T.; Pitarresi, G.; Badagliacco, D.; Fiore, V.; Valenza, A. Mechanical properties of basalt fiber reinforced composites manufactured with different vacuum assisted impregnation techniques. Compos. Part B Eng. 2016, 104, 35-43. [CrossRef]

16. Wu, G.; Wang, X.; Wu, Z.; Dong, Z.; Zhang, G. Durability of basalt fibers and composites in corrosive environments. J. Compos. Mater. 2015, 49, 873-887. [CrossRef]

17. Matkó, S.; Anna, P.; Marosi, G.; Szep, A.; Keszei, S.; Czigany, T.; Pölöskei, K. Use of reactive surfactants in basalt fiber reinforced polypropylene composites. In Macromolecular Symposia; WILEY-VCH Verlag: Weinheim, Germany, 2003; pp. 255-268.

18. Czigány, T. Basalt fiber reinforced hybrid polymer composites. In Materials Science Forum; Trans Tech Publications: Zürich, Switzerland, 2005; pp. 59-66.

19. Bashtannik, P.; Ovcharenko, V.; Boot, Y.A. Effect of combined extrusion parameters on mechanical properties of basalt fiber-reinforced plastics based on polypropylene. Mech. Compos. Mater. 1997, 33, 600-603. [CrossRef]

20. Liu, Q.; Shaw, M.T.; Parnas, R.S.; McDonnell, A.M. Investigation of basalt fiber composite aging behavior for applications in transportation. Polym. Compos. 2006, 27, 475-483. [CrossRef]

21. Jancar, J. Effect of interfacial shear strength on the mechanical response of polycarbonate and PP reinforced with basalt fibers. Compos. Interfaces 2006, 13, 853-864. [CrossRef]

22. Artemenko, S. Polymer composite materials made from carbon, basalt, and glass fibres. Structure and properties. Fibre Chem. 2003, 35, 226-229. [CrossRef]

23. Wei, B.; Cao, H.; Song, S. Tensile behavior contrast of basalt and glass fibers after chemical treatment. Mater. Des. 2010, 31, 4244-4250. [CrossRef]

24. Manikandan, V.; Jappes, J.W.; Kumar, S.S.; Amuthakkannan, P. Investigation of the effect of surface modifications on the mechanical properties of basalt fibre reinforced polymer composites. Compos. Part B Eng. 2012, 43, 812-818. [CrossRef]

25. Park, J.-M.; Shin, W.-G.; Yoon, D.-J. A study of interfacial aspects of epoxy-based composites reinforced with dual basalt and $\mathrm{SiC}$ fibres by means of the fragmentation and acoustic emission techniques. Compos. Sci. Technol. 1999, 59, 355-370. [CrossRef]

26. Mangat, P.S. Strength and deformation characteristics of an acrylic polymer-cement composite. Matér. Constr. 1978, 11, 435-443. [CrossRef] 
27. Girgin, Z.C.; Yıldırım, M.T. Usability of basalt fibres in fibre reinforced cement composites. Mater. Struct. 2016, 49, 3309-3319. [CrossRef]

28. Alaimo, G.; Valenza, A.; Enea, D.; Fiore, V. The durability of basalt fibres reinforced polymer (BFRP) panels for cladding. Mater. Struct. 2016, 49, 2053-2064. [CrossRef]

29. Abdellah, M.Y.; Gelany, A.; Mohamed, A.F.; Khoshaim, A.B. Protection of limestone coated with different polymeric materials. Am. J. Mech. Eng. 2017, 5, 51-57. [CrossRef]

30. Abdellah, M.Y. Delamination modeling of double cantilever beam of unidirectional composite laminates. Fail. Anal. Prev. 2017, 17, 1011-1018. [CrossRef]

31. Abdellah, M.Y.; Hassan, M.K.; El-Ainin, H.A. Plasticity and formability controlling of cast iron using thermo-mechanical treatment. Am. J. Mater. Eng. Technol. 2014, 2, 38-42.

32. Fiore, V.; Scalici, T.; di Bella, G.; Valenza, A. A review on basalt fibre and its composites. Compos. Part B Eng. 2015, 74, 74-94. [CrossRef]

33. Sudeepan, J.; Kumar, K.; Barman, T.K.; Sahoo, P. Study of mechanical and tribological properties of ABS/ZnO polymer composites. Adv. Mater. Manuf. Charact. 2015, 5, 1-11. [CrossRef]

34. Zhang, X.; Pei, X.; Wang, Q. Friction and wear properties of basalt fiber reinforced/solid lubricants filled polyimide composites under different sliding conditions. J. Appl. Polym. Sci. 2009, 114, 1746-1752. [CrossRef]

35. Mohamed, K.H.; Mohammed, Y.A.; Azabi, S.K.; Marzouk, W.W. Investigation of the mechanical behavior of novel fiber metal laminates. Int. J. Mech. Mechatron. Eng. 2015, 15, 112-118.

36. LG Chem. Available online: http://www.lgchem.com.tr/index.php (accessed on 25 October 2015).

37. Ahmed, F.M.; Mohammed, Y.A.; Mohammed, K.H. Relaxation and compressive characteristic in composite glass fiber reinforced pipes. Int. J. Sci. Eng. Res. 2015, 6.

38. Militký, J.; Kovačič, V.; Bajzík, V. Mechanical properties of basalt filaments. Fibres Text. Eastern Eur. 2007, 15, 64-65.

39. Militký, J.; Kovačič, V.R.; Rubnerová, J. Influence of thermal treatment on tensile failure of basalt fibers. Eng. Fract. Mech. 2002, 69, 1025-1033. [CrossRef]

40. ASTM D3039/D 3039M. Standard Test Method for Tensile Properties of Polymer Matrix Composite Materials; ASTM International: West Conshohocken, PA, USA, 1995.

41. ASTM D6110-17. Standard Test Method for Determining the Charpy Impact Resistance of Notched Specimens of Plastics; ASTM International: West Conshohocken, PA, USA, 2017.

42. ASTM D785-08. Standard Test Method for Rockwell Hardness of Plastics and Electrical Insulating Materials; ASTM International: West Conshohocken, PA, USA, 2005.

43. ASTM G132-96. Standard Test Method for Pin Abrasion Testing; ASTM international: West Conshohocken, PA, USA, 2013.

44. Chotirat, L.; Chaochanchaikul, K.; Sombatsompop, N. On adhesion mechanisms and interfacial strength in acrylonitrile-butadiene-styrene/wood sawdust composites. Int. J. Adhes. Adhes. 2007, 27, 669-678. [CrossRef]

45. Wu, S. Phase structure and adhesion in polymer blends: A criterion for rubber toughening. Polymer 1985, 26, 1855-1863. [CrossRef]

46. Margolina, A.; Wu, S. Percolation model for brittle-tough transition in nylon/rubber blends. Polymer 1988, 29, 2170-2173. [CrossRef]

47. Nakamura, Y.; Yamaguchi, M.; Okubo, M.; Matsumoto, T. Effect of particle size on the fracture toughness of epoxy resin filled with spherical silica. Polymer 1992, 33, 3415-3426. [CrossRef]

48. Bahadur, S.; Gong, D. The action of fillers in the modification of the tribological behavior of polymers. Wear 1992, 158, 41-59. [CrossRef]

(C) 2018 by the authors. Licensee MDPI, Basel, Switzerland. This article is an open access article distributed under the terms and conditions of the Creative Commons Attribution (CC BY) license (http:/ / creativecommons.org/licenses/by/4.0/). 